OPEN ACCESS

Edited by: Marissa Zwald, Washington University in St. Louis,

Reviewed by: Tamar A. Klaiman, University of the Sciences in Philadelphia, USA Gregory Wayne Heath, University of Tennessee at Chattanooga, USA

*Correspondence: Jamie F. Chriqui jchriqui@uic.edu

Specialty section: This article was submitted to

Public Health Policy,

a section of the journal Frontiers in Public Health

Received: 11 January 2016 Accepted: 03 April 2016 Published: 18 April 2016

Citation:

Chriqui JF, Leider J, Thrun E, Nicholson LM and Slater S (2016)

Communities on the Move: Pedestrian-Oriented Zoning as a Facilitator of Adult Active Travel to Work in the United States. Front. Public Health 4:71. doi: 10.3389/fpubh.2016.00071

\section{Communities on the Move: Pedestrian-Oriented Zoning as a Facilitator of Adult Active Travel to Work in the United States}

\author{
Jamie F. Chriqui ${ }^{1,2 *}$, Julien Leider ${ }^{1}$, Emily Thrun ${ }^{1}$, Lisa M. Nicholson ${ }^{1}$ and Sandy Slater ${ }^{1,2}$ \\ ${ }^{1}$ Institute for Health Research and Policy, University of Illinois at Chicago, Chicago, IL, USA, ${ }^{2}$ Division of Health Policy and \\ Administration, School of Public Health, University of Illinois at Chicago, Chicago, IL, USA
}

Background: Communities across the United States have been reforming their zoning codes to create pedestrian-friendly neighborhoods with increased street connectivity, mixed use and higher density, open space, transportation infrastructure, and a traditional neighborhood structure. Zoning code reforms include new urbanist zoning such as the SmartCode, form-based codes, transects, transportation and pedestrian-oriented developments, and traditional neighborhood developments.

Purpose: To examine the relationship of zoning code reforms and more active living-oriented zoning provisions with adult active travel to work via walking, biking, or by using public transit.

Methods: Zoning codes effective as of 2010 were compiled for 3,914 municipal-level jurisdictions located in 471 counties and 2 consolidated cities in 48 states and the District of Columbia, and that collectively covered $72.9 \%$ of the U.S. population. Zoning codes were evaluated for the presence of code reform zoning and nine pedestrian-oriented zoning provisions $(1=$ yes): sidewalks, crosswalks, bike-pedestrian connectivity, street connectivity, bike lanes, bike parking, bike-pedestrian trails/paths, mixed-use development, and other walkability/pedestrian orientation. A zoning scale reflected the number of provisions addressed (out of 10). Five continuous outcome measures were constructed using 2010-2014 American Community Survey municipal-level 5-year estimates to assess the percentage of workers: walking, biking, walking or biking, or taking public transit to work OR engaged in any active travel to work. Regression models controlled for municipal-level socioeconomic characteristics and a GIS-constructed walkability scale and were clustered on county with robust standard errors.

Results: Adjusted models indicated that several pedestrian-oriented zoning provisions were statistically associated ( $p<0.05$ or lower) with increased rates of walking, biking, or engaging in any active travel (walking, biking, or any active travel) to work: code reform zoning, bike parking (street furniture), bike lanes, bike-pedestrian trails/paths, other walkability, mixed-use zoning, and a higher score on the zoning scale. Public transit use was associated with code reform zoning and a number of zoning measures in Southern jurisdictions but not in non-Southern jurisdictions.

Conclusion: As jurisdictions revisit their zoning and land use policies, they may want to evaluate the pedestrian-orientation of their zoning codes so that they can plan for pedestrian improvements that will help to encourage active travel to work.

Keywords: zoning, land use, active travel, physical activity, built environment, policy 


\section{INTRODUCTION}

The Physical Activity Guidelines for Americans recommend that adults get at least 150 min a week of moderate intensity physical activity (PA) through activities such as brisk walking or bicycling on ground level or an area with few hills or 75 min weekly of vigorous intensity PA through such activities as running or jogging $(1$, 2). However, most Americans PA levels fall far below the recommendations. In fact, the majority of Americans (52\%) do not meet the Physical Activity Guidelines and the national median of adults who do not engage in any $\mathrm{PA}$ is $22.6 \%(3,4)$. Furthermore, rates of inactivity are highest among adults living in the South, which is also the region of the country with the highest rates of obesity (4). Thus, reducing the proportion of adults who are inactive and increasing the proportion of adults who meet the Guidelines have been deemed priorities in Healthy People $2020(5,6)$.

Among physically active adults, walking was reported as one of the top two activities in which the majority of male and female adults reported being engaged (7). In 2011, more than $60 \%$ of adults reported walking for at least $10 \mathrm{~min}$ in the past week for transportation or leisure purposes (8); however, less than one-third of adults reported walking specifically for transportation purposes (9). Because walking is the easiest form of PA to incorporate into Americans' daily lives, the U.S. Surgeon General recently issued a Call to Action to Promote Walking and Walkability (10).

While most Americans will derive their PA from leisure-time activities, additional PA can be garnered through active travel to destinations such as shopping, work, and school (11). Active travel to work can provide additional minutes of moderate intensity PA, and it can be achieved by walking, bicycling, or through public transit use, which involves walking and bicycling to/from public transit stops to work or other destinations. Studies have reported that adults who engage in active travel to work, particularly through walking, have overall higher levels of PA as compared to adults who do not engage in active travel to work (12-15). And adults living in more walkable neighborhoods report engaging in up to 44.3 min per week of moderate intensity PA as compared to only 12.8 min per week in neighborhoods considered to be less walkable (16).

Numerous authoritative bodies have recognized the role that community and street-scale design can play in facilitating PA and active travel (10,17-20). Community characteristics that facilitate active travel and PA include mixed-use (MU) developments and traditional neighborhood design that provide street and sidewalk connectivity and transportation infrastructure $(17,21-27)$. And, adult walking is associated with more compact neighborhoods with dense street connectivity and MU development (22, 23, 28-33). Whereas, less compact or more sprawling communities and communities with limited transportation infrastructure, poor street/sidewalk connectivity, lack of sidewalks or bike paths, single use zoning, and high traffic volume tend to have lower rates of active travel and/or PA (22-24, 34-36).

One of the primary tools that local planning and zoning officials have to effectuate changes to community- and street-scale design is through their zoning codes and land use regulations (37). Historically, zoning codes were written to permit land uses based on a zoning map that divides land into specific uses, typically single-uses such as only allowing commercial developing in commercial zones or only allowing residential development in residential zones rather than allowing a mix of residential and commercial development in MU zones $(35,38)$. And, traditional, or Euclidian zoning approaches, have contributed to sprawling, automobile-reliant communities (24, 35, 39-42). Land use changes have been shown to affect people's behavior over time $(26,43)$ with MU, street-scale design, and accessibility and street connectivity all demonstrating important co-benefits in improving physical health (26).

Typically, local development plans (often referred to as "master," "comprehensive," or "general growth" plans) are developed by local planning and zoning bodies to provide a "road map" or to guide local land use planning decisions (38). Technically, plans are implemented through changes to zoning codes/regulations $(38,44)$. In recent years, triggered in part by the SmartGrowth and New Urbanism movements, communities nationwide have been reforming their zoning and land use codes and regulations to create more pedestrian-oriented neighborhoods with increased street connectivity, MU and higher density, open space, transportation infrastructure, and a traditional neighborhood structure $(35,38,39,44,45)$. These zoning code reforms include traditional neighborhood developments (TND), form-based codes, the SmartCode, and pedestrian-/transit-oriented developments (POD and TOD) all with a common goal of emphasizing walkability; and promoting MU that provides easy walking access to transport, worksites, shopping, entertainment and recreation; and emphasizing amenities and infrastructure that are associated with walking and biking behaviors including street furniture, bike lanes and bike parking, and crosswalks (35, 38, 39, 46-54). Notably, the SmartCode was developed by an architecture and town planning firm in Florida and initially diffused throughout Florida and the Southern region of the country (49). Additionally, following Hurricane Katrina in 2005, many communities along the Gulf Coast had to rebuild and used that as an opportunity to revamp their zoning codes with many opting for new urbanist and form-based codes $(55,56)$.

To our knowledge, no study has explored the relationship between zoning codes nationwide and active travel to work. One recent study by the current authors examined the association between zoning codes and zoning code reforms and adult leisure-time PA and found that code reforms and more active living-oriented zoning provisions (e.g., zoning requirements for mixed use, bike parking/street furniture, and bike-pedestrian trails/paths) were associated with increased odds of adult leisuretime biking and walking (57). Another study conducted in 22 California cities found that MU zoning was associated with the mix, breadth, and depth of walking destinations in the mixed-use zones within the cities (58). However, neither study examined the relationship between zoning and active travel to work. We sought to address this gap by assessing the relationship between zoning codes nationwide, including zoning code reforms and active living-oriented zoning provisions, and adult active travel to work in municipal jurisdictions nationwide and separately for Southern vs. non-Southern jurisdictions. Based on the literature reviewed above, we hypothesized that adult active travel to work 
would be greater in municipalities with code reform zoning and in jurisdictions with more active living-oriented zoning requirements.

\section{MATERIALS AND METHODS}

This cross-sectional study was conducted between May 2012 and June 2015. The University of Illinois at Chicago (UIC) Institutional Review Board deemed that this study did "not involve human subjects” (research protocol \#2011-0880).

\section{Sample}

The initial sample frame was a purposeful sample of all municipal jurisdictions located in the most populous 496 counties and 4 consolidated cities in the U.S. which collectively comprised $75.35 \%$ of the U.S. population. However, because this study was focused on municipal zoning, 24 of the counties were dropped from the frame because they did not contain any municipalities. As a result, the sample frame was comprised of a census of all 6,438 municipal jurisdictions in 472 counties and 4 consolidated cities, which collectively covered $73.28 \%$ of the U.S. population. Due to resource constraints, the frame was then limited to only those jurisdictions that comprised at least $0.5 \%$ of each county population. The excluded cases did not differ from the rest of the sample other than the fact that they were very small jurisdictions covering very small land areas. With this restriction, the final sample included 4,076 jurisdictions located in 472 counties and 3 consolidated cities. Although the restriction reduced the municipal jurisdiction sample size, it excluded very small jurisdictions that, in aggregate, included only $3 \%$ of the population covered by the initial sample frame and less than $2 \%$ of the U.S. population. The final sample of 4,076 jurisdictions were located in 472 counties and 3 consolidated cities in 48 states and the District of Columbia, and that collectively covered $73.01 \%$ of the U.S. population.

We could not obtain the zoning code for 155 of these jurisdictions, data needed to construct our walkability scale (detailed below) for another 6, and American Community Survey (ACS) data for one other; thus, the final analytic sample included 3,914 jurisdictions in 471 counties and 2 consolidated cities in 48 states and the District of Columbia. The counties and consolidated cities in which these jurisdictions were located covered $72.90 \%$ of the U.S. population.

\section{Data Sources}

\section{Zoning Codes}

Hard or electronic copies of the zoning codes (including zoning code reforms such as the SmartCode and form-based codes) were compiled for all 3,914 jurisdictions included in the analysis between May 2012 and May 2015. In order to facilitate a lag with the active transport outcomes, we obtained zoning codes that were effective as of 2010. (Notably, while we obtained the zoning codes as of 2010 because of the time period for the zoning code collection, anecdotally we noticed that many of the codes had been in place for years if not decades prior.) All of the zoning codes were collected via Internet research with 100\% telephone follow-up to verify complete and accurate collection. In instances where the zoning code had been updated post-2010, we obtained the version in effect as of 2010 .

\section{American Community Survey}

Municipal-level characteristics and active travel to work measures were obtained from the Census Bureau's ACS 2010-2014 5 -year estimates (59). The ACS is an annual survey that provides socio-demographic characteristics for each jurisdiction. We used the 5-year ACS estimates because they are available for jurisdictions of all sizes nationwide, which was necessary as our sample was restricted to all jurisdictions containing more than $0.5 \%$ of their county/consolidated city's population, and included small jurisdictions not captured in the 1- and 3-year estimates. The 5 -year estimates are also the most precise (60).

\section{NAVTEQ}

ArcGIS 10.1 software was used to access NAVTEQ 2013 data. NAVTEQ data provided counts of four-way vs. all street level intersections for each jurisdiction. These data were combined with other measures to create a walkability scale described below.

\section{Measures}

\section{Active Transport Outcomes}

Separate variables capturing the percentage of workers walking, biking, or taking public transportation to work were derived from one ACS question: "How did this person usually get to work LAST WEEK? If this person usually used more than one method of transportation during the trip, mark (X) in the box of the one used for most of the distance." The response options included: car, truck, or van; bus or trolley bus; streetcar or trolley car; subway or elevated; railroad; ferryboat; taxicab; motorcycle; bicycle; walked; worked at home; or other method. From this list, we constructed three active travel to work measures: walked, bicycled, or took public transit. The public transit measure was derived from positive responses to taking bus or trolley bus, streetcar or trolley car, subway or elevated, railroad, or ferryboat. Additionally, because of the low prevalence of active travel to work (see Results), we created two additional composite measures: one capturing the percentage of workers who either walked or biked to work, and another capturing the percentage of workers who took any form of active transportation (walking, biking, or public transportation) to work.

\section{Zoning Elements}

Master's level urban planners reviewed and coded the zoning codes using a zoning code audit tool and detailed coding protocol developed by the study team to assess the type of zoning (code reform vs. traditional, Euclidean) and the degree to which zoning policies addressed active living-oriented provisions (see the Supplementary Material for the coding tool). Each coder was tested for inter-rater reliability and was not allowed to code independently until they reached a $90 \%$ agreement rate. Two Research Electronic Data Capture (REDCap) databases were developed to capture policy collection and coding data entry (61). 
A dichotomous (yes/no) variable was created to capture whether each jurisdiction's zoning code contained zoning code reforms (e.g., SmartCodes, form-based codes, or new urbanist, pedestrian-oriented, transit-oriented, or traditional neighborhood development districts). Each zoning code was also assessed for eight types of zones/districts (code reform, commercial, mixed use, park/recreation/open space, planned unit development, public/civic/government, residential, and general zoning) and, within each zone/district, we examined whether any of the following nine active living-oriented provisions that promote PA and active travel to work were addressed: sidewalks; crosswalks; bike/pedestrian connectivity; street connectivity; bike lanes; bike parking; trails/paths; mixed use; and other general walkability provisions (e.g., traffic calming and pedestrian measures). For each zoning code provision, a dichotomous variable was created to indicate whether the given provision was addressed in any zone/district (e.g., crosswalks addressed in any of the zones/districts examined) within the jurisdiction. We also constructed a zoning provision scale with a maximum value of 10 which equals the number of addressed provisions (maximum value of $10=$ each of the 9 provisions was addressed and the jurisdiction had code reform zoning).

\section{Municipal-Level Controls}

Tertiles of median household income and population size were generated from the ACS 2010-2014 data, as were the percentage of households in poverty, percent non-Hispanic White, percent non-Hispanic Black, percent Hispanic, median age, percent of occupied housing with no vehicle available, and region. To at least partially account for the built environment in each municipality, we created a standardized walkability scale using NAVTEQ 2013 and ACS 2010-2014 data. The walkability scale was standardized and adjusted by a factor of one to reduce negative scale values and is a summated scale of four density measures: the ratio of four-way intersections to all intersections (NAVTEQ), intersection density or the total number of intersections in the municipality divided by the municipal land area (NAVTEQ), housing unit density (ACS), and population density (ACS). The walkability scale was based on the scale created by Slater and colleagues which was adapted from the scale created and updated by Ewing and colleagues $(36,62)$.

\section{Statistical Analysis}

The zoning, ACS, and NAVTEQ data were linked using municipallevel Federal Information Processing Standards (FIPS) geocodes. Mean levels of active travel to work by the presence or absence of code reform zoning and our nine active living-oriented zoning provisions were computed to show the unadjusted association between code reform and active living-oriented zoning and active travel to work. $T$-tests were computed with no assumption of equal variances using Satterthwaite's approximation to test the statistical significance of differences in mean levels of active transport with and without code reform zoning and each of the nine zoning provisions. Additionally, mean levels of active travel to work were computed for each level of the zoning provision scale. Finally, multivariate linear regressions were computed to examine the relationship between active living-oriented zoning and active travel to work conditional on jurisdiction controls.
Additionally, given that the highest rates of adult inactivity are in Southern states (4) and that code reform zoning emerged in the South $(49,55,56)$, we wanted to assess whether there were differences in the relationship between zoning and active travel behaviors in the South vs. other regions of the country. To do so, the prevalence of code reform zoning and each of the nine zoning provisions were computed in Southern and non-Southern jurisdictions using Census regional classifications. Bivariate $t$-tests with no assumption of equal variances were used to assess whether zoning varied by Southern region vs. non-Southern region. Multivariate linear regressions linking active livingoriented zoning to active travel to work were then run separately for Southern and non-Southern jurisdictions.

All regression models were clustered on county with robust standard errors and controlled for the jurisdiction characteristics listed above. Adjusted $R^{2}$ statistics were computed to assess model fit. All analyses were conducted using Stata S.E. version 13 (63).

\section{RESULTS}

\section{Sample Characteristics}

Descriptive statistics for the sample are presented in Table $\mathbf{1}$. Briefly, the majority of municipalities' zoning codes addressed sidewalks (78\%), pedestrian access/other walkability (73\%), mixed-use development (68\%), and bike-pedestrian trails or paths (57\%). Zoning for the other pedestrian-related provisions ranged from $11 \%$ (bike lanes) to $37 \%$ (bike-pedestrian connectivity). Fourteen percent of the jurisdictions had code reform zoning. On average, municipalities' zoning codes included 4.27 out of the 10 possible zoning measures.

While some communities had relatively high rates of active travel to work (i.e., the maximum rates were $46.97 \%$ walking to work, $64.14 \%$ taking public transit, and $23.07 \%$ bicycling to work), on average, the rates of active travel were non-existent or very low. Across all jurisdictions, an average of only $2.65 \%$ of respondents walked to work, $3.11 \%$ took public transit to work, and $0.48 \%$ biked to work. Overall, $6.25 \%$ of respondents engaged in some form of active travel to work.

The municipalities were located in all four Census regions, and their distribution is consistent with the national distribution of population by region. On average, rates of household poverty were low (12.54\%), the vast majority of communities had large percentages of non-Hispanic White residents (71.19\%), the median resident age was 38.28 years, and $7.15 \%$ of occupied households reported having no vehicle available. Median household income rates ranged from a low of $\$ 17,281$ to a maximum of $>\$ 250,000$. The size of the municipalities ranged from very small ( $\sim 50$ people) to very large, populous cities (more than two million people). And, the mean score on the walkability scale was 1 with a maximum score of 23.39 .

\section{Bivariate Prevalence of Active Travel to Work by Zoning Measure}

Table 2 presents the bivariate summary statistics of prevalence of each form of active travel to work by each zoning measure. In the 
TABLE 1 | Descriptive statistics for the municipal sample.

\begin{tabular}{|c|c|c|c|c|}
\hline Variable & $\begin{array}{l}\% \text { or } \\
\text { mean }\end{array}$ & SD & Min & Max \\
\hline \multicolumn{5}{|c|}{ Policy predictors-Zoning Provisions (\%) } \\
\hline Code reform zoning & 0.14 & 0.35 & 0 & 1 \\
\hline Sidewalks & 0.78 & 0.42 & 0 & 1 \\
\hline Crosswalks & 0.22 & 0.42 & 0 & 1 \\
\hline Bike-pedestrian connectivity & 0.37 & 0.48 & 0 & 1 \\
\hline Street connectivity & 0.34 & 0.48 & 0 & 1 \\
\hline Bike lanes & 0.11 & 0.31 & 0 & 1 \\
\hline Bike parking & 0.32 & 0.47 & 0 & 1 \\
\hline Bike-pedestrian trails/paths & 0.57 & 0.50 & 0 & 1 \\
\hline Other walkability & 0.73 & 0.45 & 0 & 1 \\
\hline Mixed use & 0.68 & 0.47 & 0 & 1 \\
\hline Zoning provision scale (max 10) (mean) & 4.27 & 2.69 & 0 & 10 \\
\hline \multicolumn{5}{|l|}{ Active travel outcomes } \\
\hline$\%$ Walk to work & 2.65 & 3.41 & 0 & 46.97 \\
\hline$\%$ Public transit to work & 3.11 & 5.75 & 0 & 64.14 \\
\hline$\%$ Bike to work & 0.48 & 1.03 & 0 & 23.07 \\
\hline$\%$ Walk or bike to work & 3.14 & 3.91 & 0 & 47.15 \\
\hline$\%$ Active travel to work (walk, bike, PT) & 6.25 & 7.70 & 0 & 87.19 \\
\hline \multicolumn{5}{|l|}{ Jurisdiction controls } \\
\hline West (\%) & 0.19 & 0.39 & 0 & 1 \\
\hline Midwest (\%) & 0.30 & 0.46 & 0 & 1 \\
\hline South (\%) & 0.28 & 0.45 & 0 & 1 \\
\hline Northeast (\%) & 0.22 & 0.41 & 0 & 1 \\
\hline$\%$ Households in poverty & 12.54 & 7.77 & 0 & 58.24 \\
\hline \% Non-Hispanic White & 71.19 & 23.91 & 0.05 & 100 \\
\hline \% Non-Hispanic Black & 8.77 & 14.11 & 0 & 96.10 \\
\hline$\%$ Hispanic & 13.58 & 17.89 & 0 & 99.61 \\
\hline \multicolumn{5}{|l|}{ Median household income tertiles } \\
\hline Low $(\$ 17,281.00-\$ 47,434.00)$ & 0.33 & 0.47 & 0 & 1 \\
\hline Middle (>\$47,434.00-\$64,924.00) & 0.33 & 0.47 & 0 & 1 \\
\hline High (>\$64,924.00->\$250,000.00) & 0.33 & 0.47 & 0 & 1 \\
\hline Median age (mean) & 38.28 & 6.37 & 12.40 & 74.50 \\
\hline $\begin{array}{l}\% \text { Occupied housing with no vehicle } \\
\text { available }\end{array}$ & 7.15 & 5.90 & 0 & 78.25 \\
\hline \multicolumn{5}{|l|}{ Population size tertiles } \\
\hline Low (509-6,083) & 0.33 & 0.47 & 0 & 1 \\
\hline Middle (>6,083-22,177) & 0.33 & 0.47 & 0 & 1 \\
\hline High (>22,177-2,712,608) & 0.33 & 0.47 & 0 & 1 \\
\hline Walkability Scale (mean) & 1.01 & 1.00 & 0.03 & 23.39 \\
\hline
\end{tabular}

$N=3914$ jurisdictions located in 471 counties and 2 consolidated cities representing $72.90 \%$ of the U.S. population, located in 48 states and the District of Columbia.

bivariate models, the only zoning measure that was statistically associated with increased rates of walking to work was mixeduse zoning ( $2.80 \%$ with mixed use vs. $2.34 \%$ without mixed use). In contrast, biking to work was significantly more common in jurisdictions with vs. without each of the zoning measures. Taking public transit to work was significantly more common in municipalities with code reform zoning and zoning provisions addressing sidewalks, crosswalks, bike parking (proxy for street furniture), other walkability/pedestrian access, and mixed-use development. Finally, in municipalities with 8 or more of the 10 zoning measures, rates of walking to work, biking to work, and engaging in any form of active travel to work were at their highest levels.

\section{Results of the Multivariate Regression Models Examining the Association between Zoning and Active Travel to Work}

The results of the adjusted models, controlling for the municipallevel controls, are presented in Table 3. This brief summary focuses on the primary active travel measures - walking to work, biking to work, and taking public transit to work - as well as the overall composite measure of engaging in any active travel to work. The results of the composite measure of walking or biking to work are only presented in the table for brevity reasons.

Code reform zoning was associated with increased rates of biking to work ( $\beta=0.13,95 \% \mathrm{CI}=0.02-0.23)$ and marginally associated with walking and taking public transit to work. Additionally, rates of walking to work were significantly higher in municipalities whose zoning codes included provisions for bike parking (our proxy for street furniture) ( $\beta=0.38,95 \%$ $\mathrm{CI}=0.14-0.62)$; bike-pedestrian trails/paths $(\beta=0.26,95 \%$ $\mathrm{CI}=0.05-0.47)$; other walkability/pedestrian access $(\beta=0.25$, $95 \% \mathrm{CI}=0.02-0.47)$; and mixed-use development $(\beta=0.30$, $95 \% \mathrm{CI}=0.10-0.50)$. Only two zoning measures were marginally associated with taking public transit to work - zoning for bike lanes and for bike parking. However, rates of biking to work were significantly higher in municipalities that zoned for sidewalks $(\beta=0.08,95 \% \mathrm{CI}=0.02-0.14)$; street connectivity $(\beta=0.08$, $95 \% \mathrm{CI}=0.01-0.15)$; bike lanes $(\beta=0.16,95 \% \mathrm{CI}=0.04-0.27)$; bike parking ( $\beta=0.30,95 \% \mathrm{CI}=0.21-0.38$ ); bike-pedestrian trails or paths $(\beta=0.07,95 \% \mathrm{CI}=0.01-0.13)$; other walkability/ pedestrian access $(\beta=0.09,95 \% \mathrm{CI}=0.03-0.15)$; and mixed-use development $(\beta=0.12,95 \% \mathrm{CI}=0.06-0.18)$. And, a higher score on the zoning scale was associated with higher rates of walking to work $(\beta=0.06,95 \% \mathrm{CI}=0.02-0.10)$ and biking to work $(\beta=0.03$, $95 \% \mathrm{CI}=0.02-0.04)$.

Because of the low prevalence of each type of active travel to work, we also examined the association between each of the zoning measures and engaging in any type of active travel to work (walking, biking, or taking public transit), which helped to increase the prevalence a bit. In these models, we found a number of zoning measures positively associated with increased rates of engaging in any active travel to work: code reform zoning ( $\beta=0.93,95 \%$ $\mathrm{CI}=0.24-1.62)$; bike lanes $(\beta=1.05,95 \% \mathrm{CI}=0.14-1.96)$; bike parking $(\beta=1.02,95 \% \mathrm{CI}=0.49-1.55)$; and other walkability $(\beta=0.61,95 \% \mathrm{CI}=0.12-1.09)$. And, for each additional zoning provision addressed, the percentage of municipal-level residents engaging in active travel to work increased by 0.13 percentage points $(\beta=0.13,95 \% \mathrm{CI}=0.04-0.23)$.

\section{Results in Southern and Non-Southern Jurisdictions}

Figure 1 presents the prevalence of code reform zoning and the nine zoning provisions in Southern and non-Southern jurisdictions. Code reform zoning is twice as prevalent in the South as outside it, and five of the nine active living-oriented zoning provisions are significantly more prevalent in the South at the $p<0.05$ level or lower.

Tables 4 and $\mathbf{5}$ show the results of the adjusted models examining the association between the zoning measures and active 
TABLE 2 | Prevalence of municipal-level active travel to work by zoning measure, 2010-2014.

\begin{tabular}{|c|c|c|c|c|c|c|c|c|c|c|c|}
\hline \multirow{2}{*}{\multicolumn{2}{|c|}{$\begin{array}{l}\text { Zoning measure (yes = zoning measure } \\
\text { present, no = zoning measure not } \\
\text { present) }\end{array}$}} & \multicolumn{10}{|c|}{ Active travel to work mode: percentage of municipal residents to ... } \\
\hline & & \multicolumn{2}{|c|}{ Walk } & \multicolumn{2}{|c|}{ Bike } & \multicolumn{2}{|c|}{ Walk or bike } & \multicolumn{2}{|c|}{ Take public transit } & \multicolumn{2}{|c|}{ Active transport ${ }^{a}$} \\
\hline & & $\%$ & $p^{\star}$ & $\%$ & $p^{*}$ & $\%$ & $p^{*}$ & $\%$ & $p^{*}$ & $\%$ & $p^{\star}$ \\
\hline \multirow[t]{2}{*}{ Code reform zoning } & Yes & 2.91 & 0.064 & 0.69 & $<0.001$ & 3.60 & 0.005 & 4.60 & $<0.001$ & 8.19 & $<0.001$ \\
\hline & No & 2.61 & & 0.45 & & 3.06 & & 2.86 & & 5.92 & \\
\hline \multicolumn{12}{|l|}{ Zoning provisions addressed } \\
\hline \multirow[t]{2}{*}{ Sidewalks } & Yes & 2.64 & 0.518 & 0.53 & $<0.001$ & 3.16 & 0.437 & 3.30 & $<0.001$ & 6.46 & $<0.001$ \\
\hline & No & 2.72 & & 0.33 & & 3.05 & & 2.46 & & 5.51 & \\
\hline \multirow[t]{2}{*}{ Crosswalks } & Yes & 2.58 & 0.496 & 0.56 & 0.023 & 3.14 & 0.962 & 3.51 & 0.044 & 6.65 & 0.126 \\
\hline & No & 2.67 & & 0.46 & & 3.14 & & 3.00 & & 6.13 & \\
\hline \multirow[t]{2}{*}{ Bike-pedestrian connectivity } & Yes & 2.54 & 0.118 & 0.56 & 0.001 & 3.10 & 0.634 & 3.28 & 0.170 & 6.38 & 0.436 \\
\hline & No & 2.72 & & 0.44 & & 3.16 & & 3.01 & & 6.18 & \\
\hline \multirow[t]{2}{*}{ Street connectivity } & Yes & 2.49 & 0.029 & 0.56 & 0.003 & 3.05 & 0.294 & 2.78 & 0.006 & 5.82 & 0.011 \\
\hline & No & 2.74 & & 0.45 & & 3.19 & & 3.29 & & 6.47 & \\
\hline \multirow[t]{2}{*}{ Bike lanes } & Yes & 2.64 & 0.902 & 0.75 & $<0.001$ & 3.39 & 0.175 & 3.49 & 0.131 & 6.88 & 0.070 \\
\hline & No & 2.66 & & 0.45 & & 3.11 & & 3.07 & & 6.18 & \\
\hline \multirow{2}{*}{$\begin{array}{l}\text { Bike parking (proxy for street } \\
\text { furniture) }\end{array}$} & Yes & 2.77 & 0.123 & 0.81 & $<0.001$ & 3.58 & $<0.001$ & 3.95 & $<0.001$ & 7.53 & $<0.001$ \\
\hline & No & 2.60 & & 0.33 & & 2.93 & & 2.71 & & 5.64 & \\
\hline \multirow[t]{2}{*}{ Bike-pedestrian trails/paths } & Yes & 2.58 & 0.117 & 0.57 & $<0.001$ & 3.15 & 0.889 & 3.04 & 0.413 & 6.19 & 0.581 \\
\hline & No & 2.75 & & 0.38 & & 3.13 & & 3.20 & & 6.33 & \\
\hline \multirow[t]{2}{*}{ Other walkability } & Yes & 2.68 & 0.388 & 0.55 & $<0.001$ & 3.23 & 0.014 & 3.41 & $<0.001$ & 6.64 & $<0.001$ \\
\hline & No & 2.57 & & 0.32 & & 2.89 & & 2.31 & & 5.20 & \\
\hline \multirow[t]{2}{*}{ Mixed use } & Yes & 2.80 & $<0.001$ & 0.57 & $<0.001$ & 3.37 & $<0.001$ & 3.38 & $<0.001$ & 6.74 & $<0.001$ \\
\hline & No & 2.34 & & 0.31 & & 2.64 & & 2.54 & & 5.18 & \\
\hline \multirow{11}{*}{$\begin{array}{l}\text { Number of zoning provisions } \\
\text { addressed (zoning scale) }\end{array}$} & 0 & 2.62 & & 0.22 & & 2.84 & & 1.77 & & 4.61 & \\
\hline & 1 & 2.39 & & 0.30 & & 2.70 & & 2.46 & & 5.16 & \\
\hline & 2 & 2.94 & & 0.36 & & 3.30 & & 3.15 & & 6.45 & \\
\hline & 3 & 2.75 & & 0.44 & & 3.19 & & 3.40 & & 6.59 & \\
\hline & 4 & 2.51 & & 0.43 & & 2.94 & & 3.23 & & 6.17 & \\
\hline & 5 & 2.38 & & 0.58 & & 2.95 & & 3.08 & & 6.03 & \\
\hline & 6 & 2.78 & & 0.57 & & 3.35 & & 3.45 & & 6.80 & \\
\hline & 7 & 2.75 & & 0.58 & & 3.33 & & 3.28 & & 6.61 & \\
\hline & 8 & 3.11 & & 0.78 & & 3.88 & & 3.43 & & 7.31 & \\
\hline & 9 & 2.50 & & 0.84 & & 3.35 & & 3.21 & & 6.56 & \\
\hline & 10 & 2.27 & & 0.62 & & 2.88 & & 4.72 & & 7.61 & \\
\hline
\end{tabular}

* $p$-value generated from a t-test comparing yes to no for each zoning measure. The t-tests were only computed for the dichotomous zoning measures and not for the zoning scale. active transport to work was computed as "yes" for ANY walking, biking, or taking public transit to work. N=3914 jurisdictions located in 471 counties and 2 consolidated cities representing $72.90 \%$ of the U.S. population, located in 48 states and the District of Columbia.

travel to work when conducted separately for Southern and non-Southern jurisdictions. While none of the zoning measures were significantly associated with public transit use in the full sample (Table 3 above), there are a number of strong significant associations when limiting the analysis to Southern jurisdictions, which do not appear among the non-Southern jurisdictions. On the other hand, results for biking to work and the composite walking or biking to work measure appear to be driven by nonSouthern jurisdictions. Overall, results for engaging in any active travel to work are strongest for Southern jurisdictions, with few significant associations between zoning and active travel among non-Southern jurisdictions but strong positive associations in the South.

\section{DISCUSSION}

As far as we know, this was the first and largest study of the prevalence of code reform zoning and active living-oriented zoning by municipalities located across the United States and their respective association with rates of adult active travel to work.
This study adds to the limited but emerging literature examining the relationship between zoning and active living and healthrelated outcomes. It also supports the theory behind new urbanist zoning that such zoning can support more pedestrian-oriented environments and activity, in this case specifically active travel to work. In fact, code reform zoning is associated with nearly a one percentage-point higher rate of active travel to work compared to non-code reform communities. Additionally, code reform zoning and certain active living-oriented zoning measures are more prevalent in the South (where code reform zoning initially emerged) and, as such, their associations with active travel to work were also stronger in the South than in non-Southern jurisdictions, particularly for public transit use and overall active travel to work.

The results of this study also are consistent with the urban planning and active living literature that has concluded that street-scale and community-scale design features are associated with higher rates of activity or active travel. While we were unable to sufficiently measure on-the-ground design features, zoning codes provide the foundation for land use design and permitted 
TABLE 3 | Adjusted associationa between municipal zoning policies and the percent of workers engaging in active travel to work, ACS 2010-2014 (full sample; $N=3914$ ).

\begin{tabular}{|c|c|c|c|c|c|c|c|c|c|c|}
\hline \multirow[t]{2}{*}{ Zoning Measure } & \multicolumn{2}{|c|}{$\%$ Walk to work ${ }^{b}$} & \multicolumn{2}{|c|}{$\begin{array}{c}\% \text { Public transit to } \\
\text { work }^{\mathrm{c}}\end{array}$} & \multicolumn{2}{|c|}{$\%$ Bike to work ${ }^{d}$} & \multicolumn{2}{|c|}{$\begin{array}{c}\% \text { Walk or bike to } \\
\text { work }^{\text {e }}\end{array}$} & \multicolumn{2}{|c|}{$\begin{array}{l}\% \text { Engage in active } \\
\text { travel to work }\end{array}$} \\
\hline & $\beta$ & $95 \% \mathrm{Cl}$ & $\beta$ & $95 \% \mathrm{Cl}$ & $\boldsymbol{\beta}$ & $95 \% \mathrm{Cl}$ & $\boldsymbol{\beta}$ & $95 \% \mathrm{Cl}$ & $\boldsymbol{\beta}$ & $95 \% \mathrm{Cl}$ \\
\hline Code reform zoning & 0.24 & $-0.00,0.48$ & 0.56 & $-0.01,1.13$ & $0.13^{\star}$ & $0.02,0.23$ & $0.36^{\star}$ & $0.07,0.66$ & $0.93^{\star \star}$ & $0.24,1.62$ \\
\hline \multicolumn{11}{|l|}{ Zoning provisions addressed } \\
\hline Sidewalks & 0.17 & $-0.07,0.40$ & 0.04 & $-0.34,0.42$ & $0.08^{\star}$ & $0.02,0.14$ & 0.25 & $-0.01,0.51$ & 0.29 & $-0.19,0.77$ \\
\hline Crosswalks & 0.12 & $-0.10,0.35$ & 0.11 & $-0.36,0.58$ & 0.07 & $-0.01,0.16$ & 0.19 & $-0.09,0.47$ & 0.30 & $-0.28,0.87$ \\
\hline $\begin{array}{l}\text { Bike-pedestrian } \\
\text { connectivity }\end{array}$ & 0.12 & $-0.08,0.33$ & 0.12 & $-0.29,0.53$ & 0.03 & $-0.05,0.10$ & 0.15 & $-0.10,0.40$ & 0.27 & $-0.24,0.78$ \\
\hline Street connectivity & 0.10 & $-0.08,0.29$ & 0.04 & $-0.32,0.40$ & $0.08^{\star}$ & $0.01,0.15$ & 0.18 & $-0.04,0.41$ & 0.23 & $-0.21,0.66$ \\
\hline Bike lanes & 0.25 & $-0.04,0.53$ & 0.65 & $-0.10,1.40$ & $0.16^{\star}$ & $0.04,0.27$ & $0.40^{\star}$ & $0.05,0.75$ & $1.05^{\star}$ & $0.14,1.96$ \\
\hline $\begin{array}{l}\text { Bike parking (proxy for } \\
\text { street furniture) }\end{array}$ & $0.38^{\star \star}$ & $0.14,0.62$ & 0.34 & $-0.06,0.74$ & $0.30^{\star \star \star}$ & $0.21,0.38$ & $0.68^{\star \star \star}$ & $0.39,0.97$ & $1.02^{\star \star \star}$ & $0.49,1.55$ \\
\hline Bike-pedestrian trails/paths & $0.26^{\star}$ & $0.05,0.47$ & -0.16 & $-0.54,0.21$ & $0.07^{\star}$ & $0.01,0.13$ & $0.32^{\star \star}$ & $0.09,0.56$ & 0.16 & $-0.29,0.61$ \\
\hline Other walkability ${ }^{g}$ & $0.25^{\star}$ & $0.02,0.47$ & 0.27 & $-0.13,0.67$ & $0.09^{\star \star}$ & $0.03,0.15$ & $0.34^{\star \star}$ & $0.09,0.59$ & $0.61^{\star}$ & $0.12,1.09$ \\
\hline Mixed use & $0.30^{\star \star}$ & $0.10,0.50$ & -0.13 & $-0.40,0.15$ & $0.12^{\star \star \star}$ & $0.06,0.18$ & $0.42^{\star \star \star ~}$ & $0.19,0.64$ & 0.29 & $-0.08,0.66$ \\
\hline $\begin{array}{l}\text { Zoning scale (0-10; \# } \\
\text { items addressed) }\end{array}$ & $0.06^{\star \star}$ & $0.02,0.10$ & 0.04 & $-0.04,0.12$ & $0.03^{\star \star \star}$ & $0.02,0.04$ & $0.09^{\star \star \star}$ & $0.05,0.14$ & $0.13^{\star \star}$ & $0.04,0.23$ \\
\hline
\end{tabular}

${ }^{a}$ All models clustered on county with robust standard errors. All models controlled for region, \% households in poverty, \% non-Hispanic white, \% non-Hispanic Black, \% Hispanic, median household income tertiles, median age, walkability scale, \% occupied housing with no vehicle available, and population size tertiles.

${ }^{b}$ Municipal-level walk to work models adjusted $R^{2}=0.26-0.27$.

cMunicipal-level public transit to work models adjusted $R^{2}=0.53$.

${ }^{\prime}$ Municipal-level bike to work models adjusted $R^{2}=0.12-0.13$.

eMunicipal-level walk OR bike to work models adjusted $R^{2}=0.26$.

${ }^{f}$ Municipal-level active travel to work models adjusted $R^{2}=0.51$.

"Other walkability includes any type of walking or bicycling provision mentioned in a code or plan that is oriented to active living that does not include our established markers. This includes phrases including the word "pedestrian" such as "pedestrian scaled development" or "pedestrian safety." It can also include traffic calming markers.

${ }^{*} p<0.05,{ }^{* *} p<0.01,{ }^{* * *} p<0.001$. Bolded items are statistically significant.

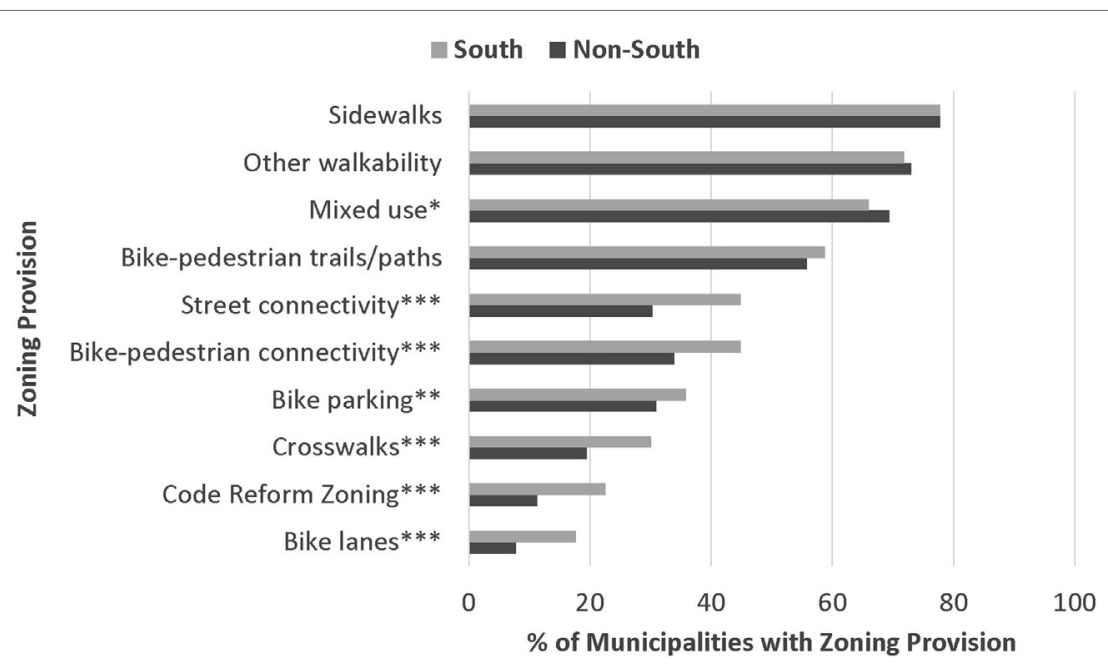

FIGURE 1 | Prevalence of zoning provisions, South vs. Non-South. $N=3914$ jurisdictions located in 471 counties and 2 consolidated cities representing $72.90 \%$ of the U.S. population, located in 48 states and the District of Columbia; $N=1108$ jurisdictions in the South and $N=2806$ jurisdictions in non-Southern regions of the country. ${ }^{\star} p<0.05,{ }^{* *} p<0.01$, and ${ }^{* \star *} p<0.001 ; p$-value generated from a t-test comparing prevalence in Southern and non-Southern jurisdictions.

land uses $(35,38,39)$. Zoning is a necessary precursor to design standards and guidelines in a community. Thus, given that many of the zoning provisions that were associated with active travel to work are consistent with the types of built environment measures associated with active travel, zoning provisions may serve as an initial proxy for measures of the built environment when they otherwise may not be readily available (as in this study). Currently, unpublished data from the study team conducted as part of the 
TABLE 4 | Adjusted associationa between municipal zoning policies and the percent of workers engaging in active travel to work, ACS 2010-2014 (Southern jurisdictions; $N=1108)$.

\begin{tabular}{|c|c|c|c|c|c|c|c|c|c|c|}
\hline \multirow[t]{2}{*}{ Zoning measure } & \multicolumn{2}{|c|}{$\%$ Walk to work ${ }^{b}$} & \multicolumn{2}{|c|}{$\begin{array}{c}\% \text { Public transit to } \\
\text { work }^{\mathrm{c}}\end{array}$} & \multicolumn{2}{|c|}{$\%$ Bike to work ${ }^{d}$} & \multicolumn{2}{|c|}{$\begin{array}{l}\% \text { Walk or bike } \\
\text { to } \text { work }^{\mathrm{e}}\end{array}$} & \multicolumn{2}{|c|}{$\begin{array}{l}\% \text { Engage in active } \\
\text { travel to work }\end{array}$} \\
\hline & $\boldsymbol{\beta}$ & $95 \% \mathrm{Cl}$ & $\beta$ & $95 \% \mathrm{Cl}$ & $\boldsymbol{\beta}$ & $95 \% \mathrm{Cl}$ & $\boldsymbol{\beta}$ & $95 \% \mathrm{Cl}$ & $\boldsymbol{\beta}$ & $95 \% \mathrm{Cl}$ \\
\hline Code reform zoning & -0.06 & $-0.35,0.24$ & $1.23^{\star \star}$ & $0.41,2.05$ & -0.04 & $-0.14,0.07$ & -0.09 & $-0.44,0.25$ & $1.13^{\star}$ & $0.12,2.15$ \\
\hline \multicolumn{11}{|l|}{ Zoning provisions addressed } \\
\hline Sidewalks & -0.01 & $-0.34,0.32$ & 0.30 & $-0.03,0.63$ & 0.07 & $-0.02,0.17$ & 0.06 & $-0.31,0.43$ & 0.37 & $-0.11,0.84$ \\
\hline Crosswalks & 0.06 & $-0.22,0.35$ & 0.60 & $-0.16,1.36$ & 0.08 & $-0.04,0.20$ & 0.14 & $-0.22,0.51$ & 0.75 & $-0.19,1.68$ \\
\hline Bike-pedestrian connectivity & 0.05 & $-0.24,0.34$ & $0.55^{\star}$ & $0.05,1.05$ & 0.05 & $-0.06,0.15$ & 0.09 & $-0.26,0.45$ & 0.64 & $-0.04,1.32$ \\
\hline Street connectivity & 0.12 & $-0.14,0.37$ & $0.67^{\star}$ & $0.15,1.19$ & 0.08 & $-0.02,0.18$ & 0.19 & $-0.11,0.50$ & $0.86^{\star \star}$ & $0.21,1.51$ \\
\hline Bike lanes & -0.13 & $-0.44,0.18$ & $1.23^{\star}$ & $0.02,2.44$ & 0.05 & $-0.08,0.18$ & -0.08 & $-0.47,0.30$ & 1.15 & $-0.29,2.59$ \\
\hline $\begin{array}{l}\text { Bike parking (proxy for street } \\
\text { furniture) }\end{array}$ & 0.17 & $-0.15,0.49$ & $1.08^{\star \star \star}$ & $0.47,1.69$ & $0.19^{\star \star}$ & $0.07,0.32$ & 0.36 & $-0.04,0.76$ & $1.44^{\star \star \star}$ & $0.65,2.23$ \\
\hline Bike-pedestrian trails/paths & 0.19 & $-0.07,0.45$ & 0.33 & $-0.02,0.68$ & 0.05 & $-0.06,0.15$ & 0.24 & $-0.07,0.55$ & $0.57^{\star}$ & $0.08,1.06$ \\
\hline Other walkabilityg & 0.19 & $-0.12,0.51$ & $0.42^{\star}$ & $0.08,0.76$ & 0.06 & $-0.05,0.18$ & 0.26 & $-0.12,0.63$ & $0.68^{\star}$ & $0.16,1.20$ \\
\hline Mixed use & 0.11 & $-0.19,0.40$ & $0.39^{\star}$ & $0.05,0.74$ & 0.08 & $-0.03,0.20$ & 0.19 & $-0.17,0.55$ & $0.59^{\star}$ & $0.08,1.09$ \\
\hline $\begin{array}{l}\text { Zoning Scale (0-10; \# items } \\
\text { addressed) }\end{array}$ & 0.02 & $-0.03,0.06$ & $0.16^{\star \star}$ & $0.04,0.27$ & $0.02^{\star}$ & $0.00,0.03$ & 0.04 & $-0.02,0.09$ & $0.19^{\star \star}$ & $0.05,0.33$ \\
\hline
\end{tabular}

${ }^{a}$ All models based on multivariate linear regressions, clustered on county with robust standard errors. All models controlled for \% households in poverty, \% non-Hispanic white, \% non-Hispanic Black, \% Hispanic, median household income tertiles, median age, walkability scale, \% occupied housing with no vehicle available, and population size tertiles.

${ }^{b}$ Municipal-level walk to work models adjusted $R^{2}=0.13$.

cMunicipal-level public transit to work models adjusted $R^{2}=0.44-0.45$.

${ }^{d}$ Municipal-level bike to work models adjusted $R^{2}=0.12-0.13$.

eMunicipal-level walk or bike to work models adjusted $R^{2}=0.15$.

${ }^{f}$ Municipal-level active transport to work models adjusted $R^{2}=0.36-0.37$.

'Other walkability includes any type of walking or bicycling provision mentioned in a code or plan that is oriented to active living that does not include our established markers. This includes phrases including the word "pedestrian" such as "pedestrian scaled development" or "pedestrian safety." It can also include traffic calming markers.

${ }^{*} p<0.05,{ }^{* *} p<0.01$, and ${ }^{* * *} p<0.001$. Bolded items are statistically significant.

TABLE 5 | Adjusted association ${ }^{a}$ between municipal zoning policies and the percent of workers engaging in active travel to work, ACS 2010-2014 (nonSouthern jurisdictions; $N=2806$ ).

\begin{tabular}{|c|c|c|c|c|c|c|c|c|c|c|}
\hline \multirow[t]{2}{*}{ Zoning measure } & \multicolumn{2}{|c|}{$\%$ Walk to work ${ }^{b}$} & \multicolumn{2}{|c|}{$\begin{array}{c}\% \text { Public transit to } \\
\text { work }^{\mathrm{c}}\end{array}$} & \multicolumn{2}{|c|}{$\%$ Bike to work ${ }^{d}$} & \multicolumn{2}{|c|}{$\begin{array}{c}\% \text { Walk or bike to } \\
\text { work }^{\mathrm{e}}\end{array}$} & \multicolumn{2}{|c|}{$\begin{array}{l}\% \text { Engage in active } \\
\text { travel to work }\end{array}$} \\
\hline & $\beta$ & $95 \% \mathrm{Cl}$ & $\beta$ & $95 \% \mathrm{Cl}$ & $\boldsymbol{\beta}$ & $95 \% \mathrm{Cl}$ & $\beta$ & $95 \% \mathrm{Cl}$ & $\boldsymbol{\beta}$ & $95 \% \mathrm{Cl}$ \\
\hline Code reform zoning & 0.34 & $-0.00,0.69$ & 0.35 & $-0.27,0.97$ & $0.24^{\star \star}$ & $0.08,0.39$ & $0.58^{\star \star}$ & $0.15,1.00$ & $0.93^{*}$ & $0.15,1.71$ \\
\hline \multicolumn{11}{|l|}{ Zoning provisions addressed } \\
\hline Sidewalks & 0.06 & $-0.24,0.36$ & -0.14 & $-0.59,0.31$ & $0.09^{\star}$ & $0.01,0.17$ & 0.15 & $-0.18,0.47$ & 0.00 & $-0.58,0.59$ \\
\hline Crosswalks & 0.05 & $-0.25,0.36$ & -0.13 & $-0.73,0.47$ & 0.07 & $-0.05,0.18$ & 0.12 & $-0.26,0.50$ & -0.01 & $-0.74,0.72$ \\
\hline Bike-pedestrian connectivity & 0.06 & $-0.20,0.33$ & -0.10 & $-0.64,0.44$ & 0.07 & $-0.03,0.18$ & 0.14 & $-0.19,0.46$ & 0.04 & $-0.64,0.71$ \\
\hline Street connectivity & -0.06 & $-0.31,0.19$ & -0.30 & $-0.73,0.14$ & 0.09 & $-0.00,0.19$ & 0.03 & $-0.27,0.33$ & -0.27 & $-0.82,0.28$ \\
\hline Bike lanes & $0.47^{\star}$ & $0.03,0.90$ & 0.24 & $-0.48,0.96$ & $0.36^{\star \star \star}$ & $0.16,0.55$ & $0.82^{\star \star}$ & $0.28,1.36$ & $1.06^{\star}$ & $0.13,1.99$ \\
\hline $\begin{array}{l}\text { Bike parking (proxy for street } \\
\text { furniture) }\end{array}$ & 0.31 & $-0.02,0.64$ & -0.06 & $-0.74,0.61$ & $0.44^{\star \star \star}$ & $0.31,0.56$ & $0.75^{\star \star \star}$ & $0.35,1.14$ & 0.68 & $-0.15,1.52$ \\
\hline Bike-pedestrian trails/paths & 0.18 & $-0.11,0.47$ & -0.44 & $-1.04,0.16$ & $0.14^{\star \star}$ & $0.05,0.23$ & 0.32 & $-0.01,0.66$ & -0.12 & $-0.84,0.61$ \\
\hline Other walkabilityg & 0.11 & $-0.20,0.42$ & 0.17 & $-0.32,0.65$ & $0.14^{\star \star \star}$ & $0.07,0.21$ & 0.25 & $-0.08,0.59$ & 0.42 & $-0.17,1.01$ \\
\hline Mixed use & 0.26 & $-0.01,0.52$ & -0.23 & $-0.58,0.13$ & $0.17^{\star \star \star \star}$ & $0.09,0.24$ & $0.42^{\star \star}$ & $0.13,0.72$ & 0.20 & $-0.28,0.67$ \\
\hline $\begin{array}{l}\text { Zoning scale (0-10; \# items } \\
\text { addressed) }\end{array}$ & 0.05 & $-0.01,0.11$ & -0.04 & $-0.15,0.07$ & $0.05^{\star \star \star}$ & $0.03,0.07$ & $0.10^{\star \star}$ & $0.03,0.17$ & 0.06 & $-0.07,0.20$ \\
\hline
\end{tabular}

${ }^{a}$ All models based on multivariate linear regressions, clustered on county with robust standard errors. All models controlled for \% households in poverty, \% non-Hispanic white, \% non-Hispanic Black, \% Hispanic, median household income tertiles, median age, walkability scale, \% occupied housing with no vehicle available, and population size tertiles.

${ }^{b}$ Municipal-level walk to work models adjusted $R^{2}=0.27$.

${ }^{c}$ Municipal-level public transit to work models adjusted $R^{2}=0.52-0.53$.

${ }^{d}$ Municipal-level bike to work models adjusted $R^{2}=0.10-0.12$.

eMunicipal-level walk or bike to work models adjusted $R^{2}=0.26-0.27$.

${ }^{t}$ Municipal-level active travel to work models adjusted $R^{2}=0.49$.

${ }^{g}$ Other walkability includes any type of walking or bicycling provision mentioned in a code or plan that is oriented to active living that does not include our established markers. This includes phrases including the word "pedestrian" such as "pedestrian scaled development" or "pedestrian safety." It can also include traffic calming markers.

${ }^{*} p<0.05,{ }^{* *} p<0.01$, and ${ }^{* * *} p<0.001$. Bolded items are statistically significant. 
Robert Wood Johnson Foundation-supported Bridging the Gap Program supports this in that we have found that built environment infrastructure is more common in jurisdictions with active living-oriented zoning (64).

With the exception of zoning for sidewalks, the measures that were consistently associated with active travel to work were those that tended to be more prevalent in the zoning codes (e.g., bike parking, bike-pedestrian trails/paths, other walkability, and MU zoning). And, not surprisingly, zoning for well-connected streets and for bike lanes was significantly associated with higher rates of biking to work. These findings lend support to recommendations for local zoning and land use policies that support community- and street-scale design features $(10,18-20,65)$. Results suggest that sidewalks alone (which are highly common) is not enough to facilitate active travel, and that communities may need built environment features that also provide better connected, and more direct routes to increase pedestrian use for work-related active travel.

Consistent with the literature, we also found that MU zoning was associated with higher rates of walking and biking to work (17, 21-26, 58). This was not surprising given that the premise behind mixed-use development is that it facilitates people living in areas where they work, shop, and play or being in close proximity to public transit that would enable them to actively commute to work.

Interestingly, rates of taking public transit to work were only marginally (at best) associated with the zoning measures in the full models; however, they were significantly associated with the zoning measures in the models restricted to Southern jurisdictions, suggesting that regional differences were masked in the full model. This is an interesting dichotomy, particularly given that rates of inactivity are higher in Southern states (4), suggesting that code reform and active living-oriented zoning may be serving as a proxy for on the ground infrastructure redevelopment that have occurred in Southern parts of the country following Hurricane Katrina, which collectively are helping to facilitate more active travel (and less inactivity) among Southern residents. Among those changes has been the prevalence of transit-oriented development (a type of zoning code reform), which would facilitate public transit use. And, one possible explanation for the lack of association with the non-Southern jurisdictions (which are less likely to have zoning code reforms or many forms of active living-oriented zoning) is that transit stops are addressed through transportation plans and design guidelines rather than being specifically addressed in the zoning codes. Future studies should consider supplementing the zoning information with other land use plans and design guidelines that would enable us to capture such information as well as complete streets policies which aim to ensure a place on the road for all users $(66,67)$. Additionally, future studies should seek to include measures of actual transit stops and service frequency within the communities to test implementation of such plans/design guidelines.

\section{Study Limitations and Areas for Future Study}

While we attempted to minimize the limitations of the study, given the scope of the study, it was impossible to account for them in their entirety. Thus, we recognize the following limitations and identify possible areas for future study to help to address the gaps that we were unable to fill herein. First, because this was a cross-sectional study and results should be interpreted as correlational rather than causational, we obviously were unable to address whether zoning is exogenous or endogenous to active travel to work behaviors. In other words, what came first - the people or the zoning? (57) Unfortunately, given the enormity of the undertaking for this study, the project timeline, and our funding, we were unable to conduct a longitudinal study to examine whether code reform and active living-oriented zoning leads to higher rates of active travel to work (endogenous effect) or whether people who prefer to or are more inclined to engage in active travel to work purposefully select communities that are zoned and designed and that have the infrastructure to support active travel to work (exogenous effect). While future studies should definitely explore issues of endogeneity and exogeneity using alternative study designs, including longitudinal studies of communities over time, advocates, planners, and public health communities should find either conclusion to be positive because both appear to be associated with more people engaging in active travel. Second, our project and data collection timeline limited the policy lag between the zoning code effective dates and the active travel outcomes. As noted earlier, based on the information compiled, we can attest that the majority of communities' zoning codes were on-the-books well before our January 2010 cutoff; however, it was not humanly possible to determine which specific zoning elements were enacted at a given point in time (e.g., was MUZ permitted as of 2007). Future, longitudinal studies using the same sample frame will be well-positioned to monitor changes in zoning prospectively now that we have been able to compile a baseline of zoning provisions in effect as of 2010. This is one of the major contributions of our study. Additionally, we used the latest possible years of active travel data for our outcomes (in fact, the ACS 2010-2014 5-year estimates were only released in December 2015) to allow for as much of a lag as possible. Future studies should examine the association and, ideally, impact of these zoning provisions using later years of outcome data to allow for more time for full-scale policy implementation. In fact, that may account for some of the reasons why certain zoning markers were not statistically associated with the active travel behaviors - they simply may not have been on-the-books for a long enough period of time to have been fully implemented. Third, unfortunately we were unable to obtain zoning maps for the 3,914 municipalities included in this study. Had we been able to obtain the zoning maps, we would have been well-positioned to code for zoning overlays which apply to a portion of a jurisdiction (e.g., business district). As such, we were unable to assess the within-jurisdiction reach or coverage for each of the zoning measures. Although this would be a resource-intensive undertaking, it is something that researchers may want to test (albeit on a smaller scale) in future studies. Fourth, our sample only comprises municipal jurisdictions in counties or consolidated cities that cover $72.90 \%$ of the U.S. population. While our coverage is vast, including jurisdictions in 48 states and the District of Columbia, the findings from this study can only be generalized to the municipalities studied herein. However, the municipalities were located in 471 of the most populous counties and 2 independent cities and they ranged from very small (as few 
as 500 people) to very large (millions of people), so we feel confident in the range of jurisdictions that were studied herein. Fifth, as noted earlier, while zoning is a key tool available to municipal planning and zoning officials that should not be overlooked, it is not the only tool at their disposal for effectuating changes to the built environment. Other such tools include but are not limited to capital improvement plans, impact fees, and design guidelines (38). Future studies should seek to examine these additional policy levers and their association with active travel to work. Finally, while we included a measure of community walkability using proven and reliable methods $(36,62)$, we were unable to test the mediating effect of on-the-ground measures of the built environment that directly corresponded to our zoning measures (e.g., trails, bike lanes, sidewalks, crosswalks, etc.). Future studies should compile such measures using regional, state, and local GIS data combined with objective assessments such as those obtained through direct observation or using innovative methods such as Google Street View photography $(68,69)$.

\section{CONCLUSION}

Despite the acknowledged limitations, this study offers new information and insight into one aspect of urban planning and land use design (i.e., zoning) that has rarely been studied on a magnitude of this scale nor have zoning provisions been associated with active travel to work behavior in communities nationwide. This study lends further credence to new urbanist theories that postulate that new urbanist zoning will create more pedestrian-friendly environments (or in our case, will be associated with more active travel to work involving walking and biking-related behaviors). And, importantly, the findings from this study support the calls by authoritative bodies such as the Surgeon General, the Institute of Medicine, and the National Physical Activity Plan for cross-sectoral collaborations and engagement in identifying and implementing strategies for facilitating adult PA, in this case active travel to work, which can lead to better population-level health outcomes.

\section{AUTHOR CONTRIBUTIONS}

JC conceptualized the study, led the writing and revision, oversaw the data collection, coding, and analysis, and was the

\section{REFERENCES}

1. U. S. Department of Health and Human Services. 2008 Physical Activity Guidelines for Americans. Washington, DC: U.S. Department of Health and Human Services; Office of Disease Prevention and Health Promotion (2008).

2. Centers for Disease Control and Prevention. How Much Physical Activity Do Adults Need?. Atlanta, GA: Centers for Disease Control and Prevention (2015). Available from: http://www.cdc.gov/physicalactivity/basics/adults/ index.htm

3. Centers for Disease Control and Prevention. Facts about Physical Activity. (2014). Available from: http://www.cdc.gov/physicalactivity/data/facts.html

4. United Health Foundation. Physical Inactivity United States. (2015). Available from: http://www.americashealthrankings.org/all/sedentary

5. Office of Disease Prevention and Health Promotion. Healthy People 2020. (2012). Available from: http://www.healthypeople.gov/2020/default.aspx

6. Office of Disease Prevention and Health Promotion. Healthy People 2020 Topics and Objectives: Physical Activity. Washington, DC: U.S. Department of principal investigator on the study. JL conducted all of the data management and analysis, drafted the methods and analysis sections, prepared the tables, and contributed to revising and finalizing the manuscript. ET led all of the zoning policy collection and coding, conducted the literature review and helped to summarize the literature, and contributed to the revision and final manuscript preparation. LN helped to conceptualize the analytic methods, led the sample construction and oversaw the compilation and cleaning of the ACS data, and contributed to the manuscript drafting and final revision. SS contributed to the study conceptualization and framing, provided input into the analyses, and provide input and helped to draft the final version of the manuscript.

\section{ACKNOWLEDGMENTS}

The authors would like to gratefully acknowledge the research and zoning coding assistance provided by Haytham Abu Zayd, MAPSS, Anthony Pelikan, MUPP, Sunny Bhat, MUPP, Erika Strauss, MUPP, Brad Gregorka, MUPP, April Jackson, PhD, MUPP, Nija Fountano, Carmen Aiken, MUPP, and Jennifer Nalbantyan, MUPP. An earlier version of this manuscript was originally presented at the Transportation Research Board's Moving Active Transport meeting in Washington, DC, USA in April 2015. The authors would also like to thank the two reviewers for their very helpful comments on an earlier version of this manuscript.

\section{FUNDING}

Funding for this study was provided by the National Cancer Institute, National Institutes of Health, under grant number R01CA158035 and by the Center for Clinical and Translational Science located within the Institute for Health Research and Policy at the University of Illinois at Chicago (grant number UL1RR029879 for the RedCap databases).

\section{SUPPLEMENTARY MATERIAL}

The Supplementary Material for this article can be found online at http://journal.frontiersin.org/article/10.3389/fpubh.2016.00071

Health and Human Services (2016). Available from: http://www.healthypeople.gov/2020/topics-objectives/topic/physical-activity/objectives

7. Watson KB, Frederick GM, Harris CD, Carlson SA, Fulton JE. U.S. adults' participation in specific activities: Behavioral Risk Factor Surveillance System - 2011. J Phys Act Health (2015) 12(Suppl 1):S3-10. doi:10.1123/ jpah.2013-0521

8. Centers for Disease Control and Prevention. Vital signs: walking among adults - United States, 2005 and 2010. MMWR Morb Mortal Wkly Rep (2012) 61(31):595-601.

9. Paul P, Carlson SA, Carroll DD, Berrigan D, Fulton JE. Walking for transportation and leisure among U.S. adults - National Health Interview Survey 2010. J Phys Act Health (2015) 12(Suppl 1):S62-9. doi:10.1123/jpah.2013-0519

10. U.S. Department of Health and Human Services. Step It Up! The Surgeon General's Call to Action to Promote Walking and Walkable Communities. Washington, DC: Office of the Surgeon General (2015).

11. de Nazelle A, Nieuwenhuijsen MJ, Antó JM, Brauer M, Briggs D, BraunFahrlander C, et al. Improving health through policies that promote active 
travel: a review of evidence to support integrated health impact assessment. Environ Int (2011) 37(4):766-77. doi:10.1016/j.envint.2011.02.003

12. Fishman E, Bocker L, Helbich M. Adult active transport in the Netherlands: an analysis of its contribution to physical activity requirements. PLoS One (2015) 10(4):e0121871. doi:10.1371/journal.pone.0121871

13. Audrey S, Procter S, Cooper AR. The contribution of walking to work to adult physical activity levels: a cross sectional study. Int J Behav Nutr Phys Act (2014) 11(1):37. doi:10.1186/1479-5868-11-37

14. Moudon AV, Lee C, Cheadle AD, Garvin C, Johnson DB, Schmid TL, et al. Attributes of environments supporting walking. Am J Health Promot (2007) 21(5):448-59. doi:10.4278/0890-1171-21.5.448

15. Pucher J, Buehler R, Bassett DR, Dannenberg AL. Walking and cycling to health: a comparative analysis of city, state, and international data. Am J Public Health (2010) 100(10):1986-92. doi:10.2105/AJPH.2009.189324

16. Sallis JF, Saelens BE, Frank LD, Conway TL, Slymen DJ, Cain KL, et al. Neighborhood built environment and income: examining multiple health outcomes. Soc Sci Med (2009) 68(7):1285-93. doi:10.1016/j. socscimed.2009.01.017

17. Heath GW, Brownson RC, Kruger J, Miles R, Powell KE, Ramsey LT, et al. The effectiveness of urban design and land use and transport policies and practices to increase physical activity: a systematic review. J Phys Activ Health (2006) 3(Suppl 1):S55-76.

18. Institute of Medicine. Local Government Actions to Prevent Childhood Obesity. Washington, DC: The National Academies Press (2009).

19. Committee on accelerating progress in obesity prevention food and nutrition board, institute of medicine of the national academies. In: Glickman D, Parker L, Sim LJ, Del Valle Cook H, Miller EA, editors. Accelerating Progress in Obesity Prevention: Solving the Weight of the Nation. Washington, DC: The National Academies Press (2012). p. 135-9.

20. National Physical Activity Plan Alliance. National Physical Activity Plan for the United States. (2010). Available from: http://www.physicalactivityplan.org/ theplan.php

21. Saelens BE, Sallis JF, Black JB, Chen D. Neighborhood-based differences in physical activity: an environment scale evaluation. Am J Public Health (2003) 93(9):1552-8. doi:10.2105/AJPH.93.9.1552

22. Saelens BE, SallisJF, Frank LD. Environmental correlates of walking and cycling: findings from the transportation, urban design, and planning literatures. Ann Behav Med (2003) 25(2):80-91. doi:10.1207/S15324796ABM2502_03

23. Ewing R, Schmid T, Killingsworth R, Zlot A, Raudenbush S. Relationship between urban sprawl and physical activity, obesity, and morbidity. Am J Health Promot (2003) 18(1):47-57. doi:10.4278/0890-1171-18.1.47

24. Handy SL, Boarnet MG, Ewing R, Killingsworth RE. How the built environment affects physical activity: views from urban planning. Am J Prev Med (2002) 23(2 Suppl):64-73. doi:10.1016/S0749-3797(02)00475-0

25. Sallis JF, Glanz K. The role of built environments in physical activity, eating, and obesity in childhood. Future Child (2006) 16(1):89-108. doi:10.1353/ foc. 2006.0009

26. Sallis JF, Spoon C, Cavill N, Engelberg JK, Gebel K, Parker M, et al. Co-benefits of designing communities for active living: an exploration of literature. Int J Behav Nutr Phys Act (2015) 12:30. doi:10.1186/s12966-015-0188-2

27. Dill J. Bicycling for transportation and health: the role of infrastructure. J Public Health Policy (2009) 30(S1):S95-110. doi:10.1057/jphp.2008.56

28. Berrigan D, PickleLW,DillJ. Associationsbetween streetconnectivity andactive transportation. Int J Health Geogr (2010) 9:20. doi:10.1186/1476-072X-9-20

29. Berrigan D, Troiano RP. The association between urban form and physical activity in U.S. adults. Am J Prev Med (2002) 23(2, Suppl 1):74-9. doi:10.1016/ S0749-3797(02)00476-2

30. Ewing R, Cervero R. Travel and the built environment: a meta-analysis. J Am Plann Assoc (2010) 76(3):265-94. doi:10.1080/01944361003766766

31. Ewing R, Meakins G, Hamidi S, Nelson AC. Relationship between urban sprawl and physical activity, obesity, and morbidity - update and refinement. Health Place (2014) 26:118-26. doi:10.1016/j.healthplace.2013.12.008

32. Ewing R, Tian G, Goates JP, Zhang M, Greenwald MJ, Joyce A, et al. Varying influences of the built environment on household travel in 15 diverse regions of the United States. Urban Stud (2014) 52(13):2330-48. doi:10.1177/0042098014560991

33. Knuiman MW, Christian HE, Divitini ML, Foster SA, Bull FC, Badland $\mathrm{HM}$, et al. A longitudinal analysis of the influence of the neighborhood built environment on walking for transportation. Am JEpidemiol (2014) 180(5):453-61. doi:10.1093/aje/kwu171

34. Day K. Active living and social justice: planning for physical activity in lowincome, Black, and Latino communities. J Am Plann Assoc (2006) 72(1):88-99. doi:10.1080/01944360608976726

35. Schilling J, Mishkovsky N. Creating a Regulatory Blueprint for Healthy Community Design: A Local Government Guide to Reforming Zoning and Land Development Codes. Washington, DC: ICMA (2005).

36. Slater SJ, Ewing R, Powell LM, Chaloupka FJ, Johnston LD, O’Malley PM. The association between community physical activity settings and youth physical activity, obesity, and body mass index. J Adolesc Health (2010) 47(5):496-503. doi:10.1016/j.jadohealth.2010.03.017

37. Steel BS, Lovrich NP. Growth management policy and county government: correlates of policy adoption across the United States. State Local Govern Rev (2000) 32:7-19. doi:10.1177/0160323X0003200101

38. American Planning Association. Planning and Urban Design Standards. Hoboken, NJ: John Wiley \& Sons, Inc (2006).

39. Schilling J, Linton LS. The public health roots of zoning: in search of active living's legal genealogy. Am J Prev Med (2005) 28(2, Suppl 2):96-104. doi:10.1016/j.amepre.2004.10.028

40. Levine J. Zoned Out: Regulation, Markets, and Choices in Transportation and Metropolitan Land Use. Washington, DC: Resources for the Future (2010).

41. Fischel WA. An economic history of zoning and a cure for its exclusionary effects. Urban Stud (2004) 41(2):317-40. doi:10.1080/0042098032000165271

42. Leinberger CB. The Option of Urbanism: Investing in a New American Dream. Washington, DC: Island Press (2007).

43. Anderson JM, MacDonald JM, Bluthenthal R, Ashwood JS. Reducing crime by shaping the built environment with zoning: an empirical study of Los Angeles. Univ PA Law Rev (2013) 161(3):699-756.

44. Norton RK. Using content analysis to evaluate local master plans and zoning codes. Land use policy (2008) 25(3):432-54. doi:10.1016/j. landusepol.2007.10.006

45. O'Connell LC. Exploring the social roots of smart growth policy adoption by cities. Soc Sci Q (2008) 89(5):1356-72. doi:10.1111/j.1540-6237.2008.00581.x

46. Form-Based Codes Institute. Form-Based Codes Defined. (2016). Available from: http://formbasedcodes.org/definition/

47. Corbitt J. Form-Based Zoning Codes: A Tool for Walkable Neighborhoods? Conference presentation at the Active Living Research Annual Meeting; San Diego, CA (2007).

48. Sitkowski RJ, Ohm BW. Form-based land development regulations. Urban Lawyer. (2006) 38(1):163-72.

49. Duany A, Sorien S, Wright W. SmartCode: Version 9.2. Gaithersburg, MD: The Town Paper (2005).

50. Davidson M, Dolnick F, American Planning Association. A Planners Dictionary. Chicago, IL: American Planning Association, Planning Advisory Service (2004).

51. Talen E. SmartCode justice [the transect]. Places (2006) 18(1):30-5.

52. Talen E. City Rules: How Regulations Affect Urban Form. Washington, DC: Island Press (2012).

53. Talen E. Zoning for and against sprawl: the case for form-based codes. J Urban Des (2013) 18(2):175-200. doi:10.1080/13574809.2013.772883

54. Rodriguez DA, Khattak AJ, Evenson KR. Can new urbanism encourage physical activity? Comparing a new urbanist neighborhood with conventional suburbs. J Am Plann Assoc (2006) 72(1):43-54. doi:10.1080/01944360608976723

55. SmartCodes Adopted Collaborative Map (2016). Available from: http://maps. google.com $/ \mathrm{maps} / \mathrm{ms} ? \mathrm{ie}=\mathrm{UTF} \& \mathrm{msa}=0 \& \mathrm{msid}=118391098176215503421.00$ $04462129034 \mathrm{~d} 7 \mathrm{~b} 59666$

56. Other Form-Based Codes Collaborative Map (2016). Available from: http:// maps.google.com $/ \mathrm{maps} / \mathrm{ms} ? \mathrm{ie}=\mathrm{UTF} \& \mathrm{msa}=0 \& \mathrm{msid}=1183910981762155034$ 21.00044622e85d6e30f6864

57. Chriqui JF, Nicholson LM, Thrun E, Leider J, Slater SJ. More active livingoriented county and municipal zoning is associated with increased adult leisure time physical activity-United States, 2011. Environ Behav (2016) 48:111-30. doi:10.1177/0013916515611175

58. Cannon CL, Thomas S, Treffers RD, Paschall MJ, Heumann L, Mann GW, et al. Testing the results of municipal mixed-use zoning ordinances: a novel methodological approach. J Health Polit Policy Law (2013) 38(4):815-39. doi:10.1215/03616878-2208612 
59. U.S. Census Bureau. 2010-2014 ACS 5-Year Estimates. (2015). Available from: http://www2.census.gov/programs-surveys/acs/summary_file/2014/ data/5_year_by_state/

60. U.S. Census Bureau. American Community Survey: When to use 1-year, 3-year, or 5-year estimates. (2015). Available from: http://www.census.gov/ programs-surveys/acs/guidance/estimates.html

61. UIC Center for Clinical Translational Science. REDCap: Research Electronic Data Capture. (2014). Available from: http://www.ccts.uic.edu/content/ redcap-research-electronic-data-capture

62. Ewing R, Hamidi S. Measuring Urban Sprawl and Validating Sprawl Measures. Washington, DC: National Institutes of Health and Smart Growth America (2014).

63. StataCorp. Stata/SE. 13.1 ed. College Station, TX: StataCorp, LP (2013).

64. Bridging the Gap Research Program. Bridging the Gap: Research Informing Policies and Practices for Healthy Youth. (2016). Available from: http://www. bridgingthegapresearch.org/

65. Khan LK, Sobush K, Keener D, Goodman K, Lowry A, Kakietek J, et al. Recommended community strategies and measurements to prevent obesity in the United States. MMWR Recomm Rep (2009) 58(RR-7):1-26.

66. ChangeLab Solutions. A Model Complete Streets Resolution for Local Governments. Oakland, CA: ChangeLab Solutions (2015).
67. Smart Growth America, The National Complete Streets Coalition. The Best Complete Streets Policies of 2014. Washington, DC: Smart Growth America (2015).

68. Kelly CM, Wilson JS, Baker EA, Miller DK, Schootman M. Using Google street view to audit the built environment: inter-rater reliability results. Ann Behav Med (2013) 45(Suppl 1):S108-12. doi:10.1007/s12160-012-9419-9

69. Wilson JS, Kelly CM, Schootman M, Baker EA, Banerjee A, Clennin M, et al. Assessing the built environment using omnidirectional imagery. Am J Prev Med (2012) 42(2):193-9. doi:10.1016/j.amepre.2011.09.029

Conflict of Interest Statement: The authors declare that the research was conducted in the absence of any commercial or financial relationships that could be construed as a potential conflict of interest.

Copyright (c) 2016 Chriqui, Leider, Thrun, Nicholson and Slater. This is an open-access article distributed under the terms of the Creative Commons Attribution License (CC BY). The use, distribution or reproduction in other forums is permitted, provided the original author(s) or licensor are credited and that the original publication in this journal is cited, in accordance with accepted academic practice. No use, distribution or reproduction is permitted which does not comply with these terms. 